\title{
Female sika deer fidelity to migration route and seasonal ranges in eastern Hokkaido, Japan
}

\author{
Mayumi Sakuragi ${ }^{1}$, Hiromasa Igota ${ }^{1, *}$, Hiroyuki Uno ${ }^{2}$, Koichi Kaji ${ }^{3}$, Masami Kaneko ${ }^{3, * *}$, \\ Rika Akamatsu ${ }^{4}$ and Koji Maekawa ${ }^{1}$ \\ ${ }^{1}$ Laboratory of Boreal Forest Conservation, Field Science Center for Northern Biosphere, Hokkaido University, Sapporo \\ 060-0809, Japan \\ ${ }^{2}$ Eastern Hokkaido Wildlife Research Station, Hokkaido Institute of Environmental Sciences, Kushiro, 085-0835, Japan \\ ${ }^{3}$ Hokkaido Institute of Environmental Sciences, Sapporo 060-0819, Japan \\ ${ }^{4}$ EnVision, Sapporo 060-0809, Japan
}

\begin{abstract}
We examined fidelity to seasonal migration routes and seasonal ranges of 10 migratory female sika deer Cervus nippon yesoensis (9 adults and 1 fawn) in eastern Hokkaido, Japan (April 1997-May 2001). Six deer did not change migration routes among years and between fall and spring migrations. Three deer used different routes between fall and spring migrations, but did not change migration routes among years in each season. When some deer changed winter ranges in some years, these ranges were located along the migration routes. These findings do indicate that migratory female sika deer show high fidelity to migration routes.
\end{abstract}

Key words: Cervus nippon, fidelity, migration route, seasonal migration, sika deer.

Many populations of large herbivores migrate seasonally between discrete home ranges (Fryxell and Sinclair 1988). Many studies have reported on seasonal migration and seasonal ranges of ungulate species in temperate ecosystem (Loft et al. 1984; Schoen and Kirchhoff 1985; Kufeld et al. 1989; Servheen and Lyon 1989; Nicholson et al. 1997; Van Deelen et al. 1998). Fidelity to seasonal ranges is common in migratory northern deer (Verme 1973; Nelson and Mech 1981; Tierson et al. 1985; Sweanor and Sandegren 1989; Mysterud 1999). In whitetailed deer (Odocoileus virginianus), matrilineal family groups of females and fawns migrate together (Nelson and Mech 1981) and show fidelity to seasonal ranges (Tierson et al. 1985; Aycrigg and Porter 1997). Franklin and Lieb (1979), Clutton-Brock et al. (1982), and Boyce (1991) demonstrated the importance of tradition in the social behavior of many populations of elk or red deer (Cervus elaphus). Fidelity to seasonal ranges may be advantageous to deer because of the knowledge which provides regarding seasonal availability of resources (Edge and Marcum 1985; Edge et al. 1985). Fidelity to seasonal ranges also contributes to stability of social groups in cervids, with attendant benefits in exploiting food resources and reducing predation (Clutton-Brock et al. 1982; Mathews 1989). However, few studies (Smith and Robbins 1994) have investigated actual migration routes and fidelity to them in terrestrial migratory mammals, probably due to the difficulty in collecting telemetry data during the migration periods. The knowledge about migration routes is essential to understand how migratory animals adapt the surrounding environment and/or topography.

Sika deer (Cervus nippon yesoensis Heude 1884) migrate seasonally between summer and winter ranges in eastern Hokkaido, Japan (Uno and Kaji 2000; Sakuragi et al. 2003; Igota et al. 2004). What migration routes do these deer use? Do deer show fidelity to migration routes? This approach is also essential for conservation biology because annual range of migratory animals is composed of both seasonal ranges and migration routes and the knowledge of the migration routes should assist managers in determining strategies for habitat manage-

*To whom correspondence should be addressed. E-mail: igota@cocoa.ocn.ne.jp

**Present address: Department of Regional Environment Studies, Faculty of Environment Systems, Rakuno Gakuen University, Ebetsu 069-8501, Japan 
ment. To examined whether sika deer show fidelity to migration routes, we tracked 10 radio-collared sika deer and then described their movements during several years.

\section{Study area}

Our study was carried out in eastern Hokkaido, Japan. Climate is cold and wet with average temperatures range from $-10.4 \mathrm{C}^{\circ}$ in February to $17.4 \mathrm{C}^{\circ}$ in August, and an average annual precipitation of 1,200 mm on Akankohan (1445'E, 4326'N) (Igarashi 1986). The Shiranuka Hills, capture site, is one of the largest and most important wintering areas for sika deer, which have been expanding their distributional range in eastern Hokkaido during the last three decades (Kaneko et al. 1998; Kaji et al. 2000). The northern high elevation regions (above $300 \mathrm{~m}$ ) are primarily composed of coniferous and mixed forests. The eastern low elevation regions (below $300 \mathrm{~m}$ ) are dominated by urban development and agriculture, but deciduous forests and plantations of Japanese larch (Larix leptolepis) persist.

\section{Materials and methods}

Ten migratory female sika deer ( 9 adults and 1 fawn) of 57 deer radio-collared in the Shiranuka Hills (Sakuragi et al. 2003; Igota et al. 2004) were analyzed to examine fidelity to migration route (Table 1, Fig. 1). Since the 10 animals were relocated relatively frequently in spite of difficulty in VHF-tracking during migration, they were chosen out of the 57 . We studied only females because behavior of deer generally varies by sexes (Miura 1976; Bowyer 1986; Scarbrough and Krausman 1988; Bowyer et al. 1996) and females are less likely to disperse than males in some cervids (Robinette 1966; Nelson and Mech 1984; Wood et al. 1989). They were located on the ground using standard triangulation procedures (STP; White and Garrott 1990) at least once a week from April 1997 to May 2001. Aerial locations were also conducted with a fixed-wing aircraft when they were lost. Location estimates, dates, and times were plotted on a $1: 25,000$ map.

Winter and summer ranges were defined as those areas within which individual deer remained during winter and summer, respectively. We considered a seasonal range as changed if the seasonal range of one year did not overlap with that of the other year at least once. Fall migration was defined as movement from summer to winter ranges, and spring migration as movement from winter to summer ranges.

Mean error for ground locations obtained from experimental transmitters for STP was $144.9 \mathrm{~m}(n=60, S D=$ 149.2). Mano (1994) reported that mean error for aerial locations was $785 \mathrm{~m}(n=10, S D=666)$ in eastern Hokkaido. We allowed a 1-km radius circular error for each location based on the location errors because we were interested in annual and seasonal variation of migration routes at a landscape scale, not at a microhabitat scale. We considered migration routes different among years or between seasons if the locations were not distributed within 2-km wide buffer connecting successive locations between seasonal ranges, based on the maximum range of the location error (diameter of $1-\mathrm{km}$ radius circular error).

Most of radio-collared deer migrated between wintering area and different summer ranges (Fig. 1), and their migration routes did not overlap. Although the 2 pairs (Deer Nos. 22, 41 AND 30, 49) used the adjacent summer ranges, respectively, they departed from summer or winter ranges on different days each other in most cases: Deer Nos. 22 and 41 in 5 of 6 migrations; Deer Nos. 30 and 49 in 3 of 4 migrations. They therefore were considered to move independently each other, basically.

\section{Results}

We obtained 302 locations for 10 migratory deer during spring and fall migrations. Based on the differences in migration route among years or between seasons, 3 types of deer were recognized in relation to use of migration route (Table 1). Fall and spring migration routes did not vary among years for 9 of 10 deer (Table 1). Migration routes of 6 (Type A) of the 9 deer also did not differ between fall and spring (Fig. 2A), while the migration routes of 3 (Type B) of the 9 deer differed between fall and spring (Fig. 2B).

One deer (No. 12; Type C) used a different spring migration route in 1997 compared to 1998 and 1999, and used a different fall migration route in 1999 compared to 1997 and 1998 (Table 1). However, migration route of deer No.12 did not differ between fall and spring except for the spring of 1997 and fall of 1999, and moreover, the eastern half of the spring migration route in 1997 did not differ from her general route (Fig. 2C). She was killed of hunting in the fall of 1999.

All of 10 deer used the same summer range among years (Table 1). On the other hand, 4 deer changed their winter ranges in some years (Table 1), but alternate 
Table 1. Individual profiles (tracking duration and age at capture), fidelity (+, changed; -, not changed) to migration routes and to seasonal ranges, and migration route use type (A, B, and C) of 10 female sika deer tracked by radio telemetry in eastern Hokkaido, Japan. See the text for descriptions of migration route use type assignment.

\begin{tabular}{|c|c|c|c|c|c|c|c|c|c|}
\hline \multirow{3}{*}{ Deer No. } & \multicolumn{2}{|c|}{ Tracking duration } & \multirow{3}{*}{$\begin{array}{l}\text { Age } \\
\text { at capture }\end{array}$} & \multicolumn{3}{|c|}{ Migration route fidelity } & \multirow{3}{*}{$\begin{array}{l}\text { Migration route } \\
\text { use type }\end{array}$} & \multirow{2}{*}{\multicolumn{2}{|c|}{ Seasonal range fidelity }} \\
\hline & \multirow{2}{*}{ Capture date } & \multirow{2}{*}{ Last date of tracking } & & \multicolumn{2}{|c|}{ Among years } & \multirow{2}{*}{$\begin{array}{c}\text { Between } \\
\text { Fall and Spring }\end{array}$} & & & \\
\hline & & & & Fall & Spring & & & Summer & Winter \\
\hline 6 & 11 April 1997 & 28 April 2001 & $\geq 3$ & - & - & - & A & - & - \\
\hline 10 & 12 April 1997 & 20 May 2000 & $\geq 3$ & - & - & - & A & - & + \\
\hline 18 & 16 April 1997 & 1 January 1999 & $\geq 3$ & - & - & - & A & - & - \\
\hline 22 & 18 March 1998 & 13 December 2000 & $\geq 3$ & - & - & - & A & - & + \\
\hline 42 & 21 March 1998 & 12 January 2000 & $\geq 3$ & - & - & - & A & - & - \\
\hline 55 & 24 March 1999 & 21 April 2001 & $\geq 3$ & - & - & - & A & - & - \\
\hline 30 & 20 March 1998 & 14 January 2000 & $\geq 3$ & - & - & + & $\mathrm{B}$ & - & + \\
\hline 41 & 19 March 1998 & 23 April 2001 & $\geq 3$ & - & - & + & $\mathrm{B}$ & - & - \\
\hline 49 & 22 March 1998 & 17 December 1999 & 0 & - & - & + & $\mathrm{B}$ & - & - \\
\hline 12 & 14 April 1997 & 8 January 2000 & $\geq 3$ & + & + & + & $\mathrm{C}$ & - & + \\
\hline
\end{tabular}

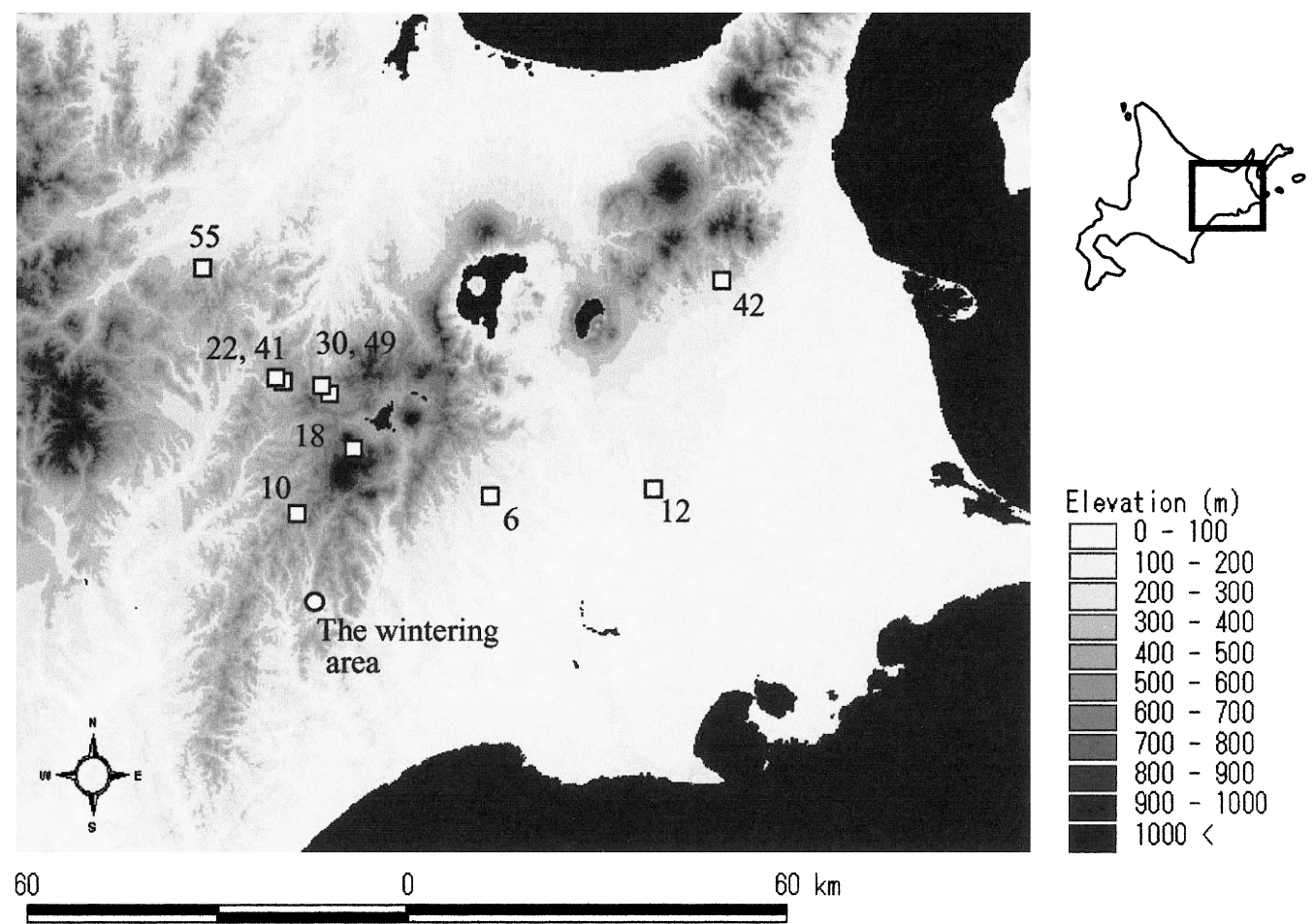

Fig. 1. Distribution of individual summer ranges (the squires) of radio-collared sika deer in eastern Hokkaido. The numbers indicate ID code of the individual deer. The circle indicates the wintering area (capture site).

winter ranges were located on the way of previously used respective migration routes (see Fig. 2C).

\section{Discussion}

Migration routes for most female sika deer did not differ among years and between seasons (Type A). Some deer used different migration routes between fall and spring, but the fall and spring migration routes did not differ among years, respectively (Type B). Although the migration route for 1 deer seemed to be irregular, it generally did not differ among years or between seasons (Type C). These findings do indicate that migratory female sika deer show high fidelity to migration routes. Fidelity to migration route as well as fidelity to seasonal ranges may be advantageous to sika deer because of the 

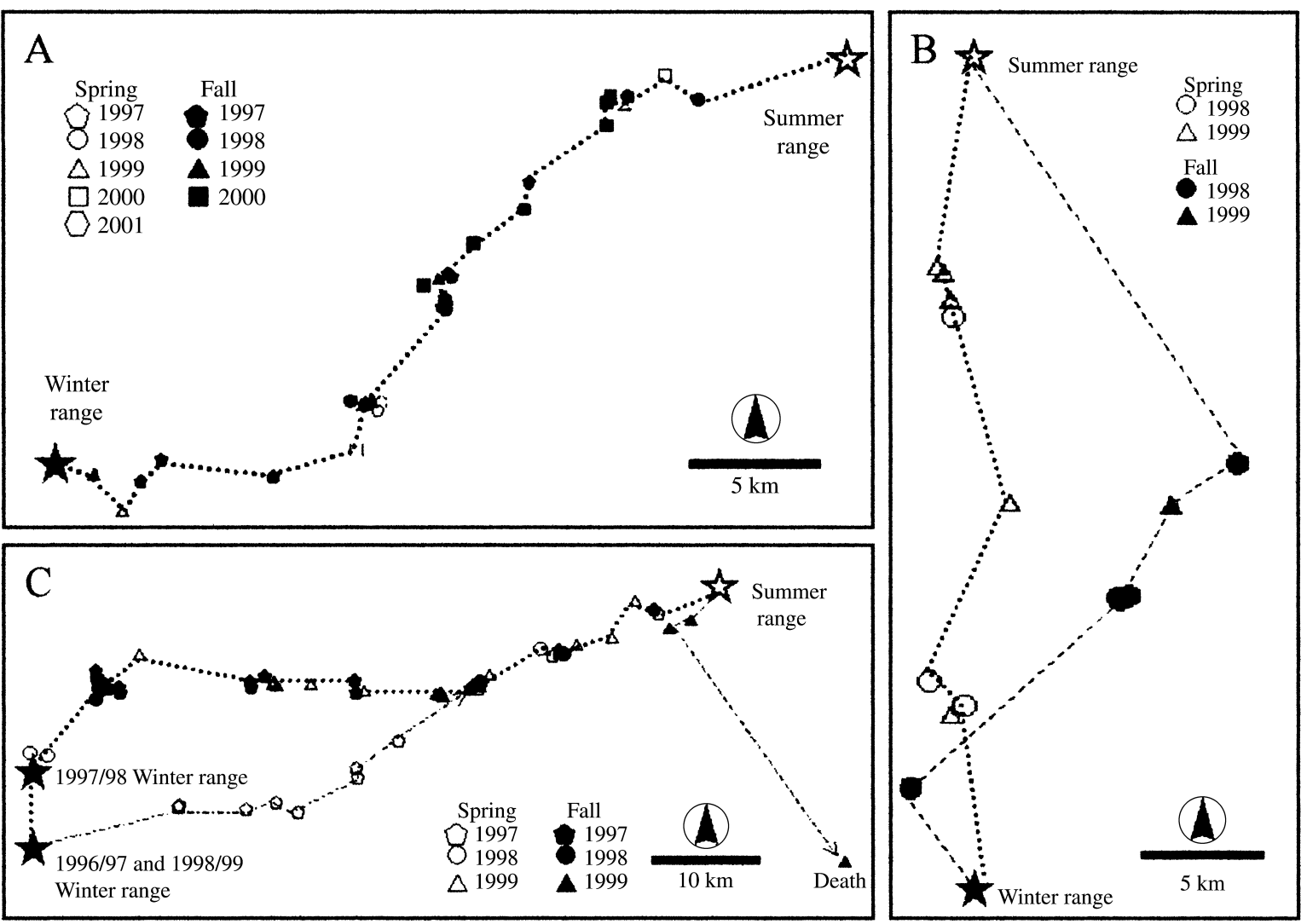

Fig. 2. Locations of sika deer Nos. 6 (A), 49 (B) and 12 (C) on their migration routes determined by radio telemetry in eastern Hokkaido, Japan. Deer Nos. 6, 49 and 12 represent deer migration route use types A, B and C, respectively. See the text for descriptions of migration route use type. Deer No. 12 also represent deer that changed winter ranges in some years. The lines connect successive locations of a migration route.

knowledge which provides regarding seasonal availability of resources or mortality sources.

Several authors reported that fidelity to a specific winter range was less than for summer range (Tierson et al. 1985; Dusek et al. 1989; Aycrigg and Porter 1997; Van Deelen et al. 1998). Our previous studies also support that fidelity to a specific winter range of sika deer was less than for summer range (Uno and Kaji 2000; Igota et al. 2004). Brown (1992) suggested that traditional use of the winter ranges might be flexible according to yearly differences in winter severity. Our findings further indicate that deer change winter ranges along used migration routes. Some deer changed winter range and yet maintained fidelity to migration routes, suggesting that use of familiar migration routes may be more advantageous to deer than movement into unfamiliar areas. One female (No. 12) in this study moved into probably unfamiliar areas and was killed of hunting. Movement into unfamiliar areas may involve high risk of mortality because of lack of the knowledge of mortality sources, just as dispersers are subjected to high mortality rates
(McCullough 1979).

Understanding of migration routes is also essential for conservation and management of migratory species, but has been rarely done for terrestrial mammals. Our understanding for the migration route of sika deer suggests that managers should pay sufficiently attention to maintain or protect the migration route of deer because deer showed high fidelity to specific migration routes.

Acknowledgments: We are very grateful to S. Hamazaki, M. Kishimoto, Y. Kamiyama, the staff of the Wildlife Management Office, EnVision, and the Hokkaido Government for capturing deer, assisting with collection of data, and supporting our work. We also thank T. Suzuki, Buheaosier, S. Shimada, S. Kameyama, and K. Waseda for helping us with the data analysis. We thank the Akan Town Office, Shiranuka Town Office, Teshikaga Town Office, and H. Sugawara for supporting our work. We acknowledge T. Doi, K. Tamada, T. Saitoh, and the students of the Laboratory of Boreal Forest Conservation, Hokkaido University for stimulating discussions. This 
study is supported by the Hokkaido Government and by a Grant-in-Aid for Scientific Research (14000353 to MS and 14340240 to KM) from the Ministry of Education, Culture, Sports, Science and Technology, and the Agency of Japan Society for the Promotion of Science. This study is also supported by the Hokkaido Government and by a Grant-in-Aid for Scientific Research (14000353 to MS and 14340240 to KM) and a 21st Century COE Program on "Neo-Science of Natural History" from the Ministry of Education, Culture, Sports, Science and Technology, and the Agency of Japan Society for the Promotion of Science.

\section{References}

Aycrigg, J. A. and Porter, W. F. 1997. Sociospatial dynamics of white-tailed deer in the central Adirondack mountains, New York. Journal of Mammalogy 78: 468-482.

Bowyer, R. T. 1986. Habitat selection by southern mule deer. California Fish and Game 72: 153-169.

Bowyer, R. T., Kie, J. G. and Ballenberghe, V. V. 1996. Sexual segregation in black-tailed deer: effects of scale. Journal of Wildlife Management 70: 10-17.

Boyce, M. S. 1991. Migratory behavior and management of elk (Cervus elaphus). Applied Animal Behavior Science 29: 239-250.

Brown, C. G. 1992. Movement and migration patterns of mule deer in southeastern Idaho. Journal of Wildlife Management 56: 246-253.

Clutton-Brock, T. H., Guinness, F. E. and Albon, S. D. 1982. Red Deer: Behavior and Ecology of Two Sexes. University of Chicago Press, Chicago, 378 pp.

Dusek, G. L., Mackie, R. J., Herriges, J. D. and Compton, B. B. 1989. Population ecology of white-tailed deer along the lower Yellowstone River. Wildlife Monographs 104: 1-68.

Edge, W. D. and Marcum, C. L. 1985. Movements of elk in relation to logging disturbances. Journal of Wildlife Management 49: 926930.

Edge, W. D., Marcum, C. L. and Olsen, S. L. 1985. Effects of logging on home range fidelity of elk. Journal of Wildlife Management 49: 741-744.

Franklin, W. L. and Lieb, J. W. 1979. The social organization of a sedentary population of North American elk: a model for understanding other populations. In (M. S. Boyce and L. D. HardenWing, eds.) North American Elk: Ecology, Behavior, and Management. Proceedings of a symposium on elk ecology and management. Pp. 85-198. University of Wyoming, Laramie, Wyoming.

Fryxell, J. M. and Sinclair, A. R. E. 1988. Causes and consequences of migration by large herbivores. Trends in Ecology and Evolution 3: 237-241.

Igarashi, T. 1986. Forest vegetation of the Akan National Park, Hokkaido, Japan. Research Bulletins of the College Experiment Forests, Faculty of Agriculture, Hokkaido University 43: 335494 (in Japanese with English summary).

Igota, H., Sakuragi, M., Uno, H., Kaji, K., Kaneko, M., Akamatsu, R. and Maekawa, K. 2004. Seasonal migration patterns of female sika deer in eastern Hokkaido, Japan. Ecological Research 19: 169-178.

Kaji, K., Miyaki, M., Saitoh, T., Ono, S. and Kaneko, M. 2000. Spatial distribution of an expanding sika deer population on Hokkaido Island, Japan. Wildlife Society Bulletin 28: 699-707.

Kaneko, M., Kaji, K. and Ono, S. 1998. Analysis of habitat change and sika deer distribution on Hokkaido. The Journal of the Mammalogical Society of Japan 38: 49-59 (in Japanese with English summary).

Kufeld, R. C., Bowden, D. C. and Schrupp, D. L. 1989. Distribution and movements of female mule deer in the Rocky Mountain foothills. Journal of Wildlife Management 53: 871-877.

Loft, E. R., Menke, J. W. and Burton, T. S. 1984. Seasonal movements and summer habitats of female black-tailed deer. Journal of Wildlife Management 48: 1317-1325.

Mano, T. 1994. A test of aerial radio-tracking for large mammals in eastern Hokkaido. In Landscape Ecological Study for Basin Management. Hokkaido Technical Center of Forest Management, Sapporo, Japan (in Japanese).

Mathews, N. E. 1989. Social structure, genetic structure, and antipredator behavior of white-tailed deer in the central Adirondacks. Dissertation, State University of New York, College of Environmental Science and Forestry, Syracuse, New York.

McCullough, D. R. 1979. The George Reserve Deer Herd: Population Ecology of a $K$-selected Species. University of Michigan Press, Ann Arbor, Michigan, 271 pp.

Miura, S. 1976. Sociological studies on sika deer in Nara park with reference to individual distribution and behavior. Annual Report of Nara Deer Research Association 3: 3-41 (in Japanese with English summary).

Mysterud, A. 1999. Seasonal migration pattern and home range of roe deer (Capreolus capreolus) in an altitudinal grandient in southern Norway. Journal of Zoology 247: 479-486.

Nelson, M. E. and Mech, L. D. 1981. Deer social organization and wolf predation in northeastern Minnesota. Wildlife Monographs 77: $1-53$

Nelson, M. E. and Mech, L. D. 1984. Home range formation and dispersal of deer in northeastern Minnesota. Journal of Mammalogy 65: 567-575

Nicholson, M. C., Bowyer, R. T. and Kie, J. G. 1997. Habitat selection and survival of mule deer: tradeoffs associated with migration. Journal of Mammalogy 78: 483-504.

Robinette, W. L. 1966. Mule deer home range and dispersal in Utah. Journal of Wildlife Management 30: 335-349.

Sakuragi, M., Igota, H., Uno, H., Kaji, K., Kaneko, M., Akamatsu, R. and Maekawa, K. 2003. Seasonal habitat selection of an expanding sika deer population in eastern Hokkaido, Japan. Wildlife Biology 9: 141-153.

Scarbrough, D. L. and Krausman, P. R. 1988. Sexual segregation by desert mule deer. The South-western Naturalist 33: 157-165.

Schoen, J. W. and Kirchhoff, M. D. 1985. Seasonal distribution and home-range patterns of Sitka black-tailed deer on Admiralty Island, Southeast Alaska. Journal of Wildlife Management 49: 96-103.

Servheen, G. and Lyon, L. J. 1989. Habitat use by woodland caribou in the Selkirk Mountains. Journal of Wildlife Management 53: 230-237.

Smith, B. L. and Robbins, R. L. 1994. Migrations and management of the Jackson elk herd. National Biological Survey Resource Publication 199.

Sweanor, P. Y. and Sandegren, F. 1989. Winter-range philopatry of seasonally migratory moose. Journal of Applied Ecology 26: 2533.

Tierson, W. C., Mattfeld, G. F., Sage, R. W. and Behrend, D. F. 1985. Seasonal movements and home-ranges of white-tailed deer in the Adirondacks. Journal of Wildlife Management 49: 760-769. 
Uno, H. and Kaji, K. 2000. Seasonal movements of female sika deer in eastern Hokkaido, Japan. Mammal Study 25: 49-57.

Van Deelen, T. R., Champa, H., Hamady, M. and Haufler, J. B. 1998. Migration and seasonal range dynamics of deer using adjacent deeryards in northern Michigan. Journal of Wildlife Management 62: 205-213.

Verme, L. J. 1973. Movements of white-tailed deer in upper Michigan. Journal of Wildlife Management 37: 545-552.
White, C. G. and Garrott, R. A. 1990. Analysis of Wildlife RadioTracking Data. Academic Press, San Diego.

Wood, A. K., Mackie, R. J. and Hamilin, K. L. 1989. Ecology of Sympatric Populations of Mule Deer and White-tailed Deer in a Prairie Environment. Montana Department of Fish, Wildlife and Parks, Bozeman, Montana, 97 pp.

Received 11 June 2004. Accepted 2 August 2004. 